\begin{tabular}{|c|c|c|c|}
\hline \multirow{3}{*}{$\begin{array}{r}\text { Case Reports in } \\
\text { Gastroenterology }\end{array}$} & \multirow{2}{*}{\multicolumn{2}{|c|}{ Case Rep Gastroenterol 2020;14:27-33 }} & \multirow[b]{3}{*}{$\begin{array}{l}\text { Karger } \\
\text { Open access }\end{array}$} \\
\hline & & & \\
\hline & $\begin{array}{l}\text { DOI: } 10.1159 / 000505511 \\
\text { Published online: January 20, } 2020\end{array}$ & $\begin{array}{l}\text { (c) } 2020 \text { The Author(s) } \\
\text { Published by S. Karger AG, Basel } \\
\text { www.karger.com/crg }\end{array}$ & \\
\hline & $\begin{array}{l}\text { This article is licensed under the } \\
\text { International License (CC BY-NC) } \\
\text { Usage and distribution for commerc }\end{array}$ & $\begin{array}{l}\text { nons Attribution-NonCommercial } 4.0 \\
\text { ger.com/Services/OpenAccessLicense). } \\
\text { uires written permission. }\end{array}$ & \\
\hline
\end{tabular}

\title{
Bowel Intussusception in Adults: Think Cancer!
}

\author{
Tarik Hadid ${ }^{a, b}$ Haidy Elazzamy ${ }^{c}$ Zyad Kafriª, \\ aDepartment of Internal Medicine, Wayne State University School of Medicine, \\ Detroit, MI, USA; 'bepartment of Internal Medicine, Ascension St. John Hospital, \\ Detroit, MI, USA; ' $\mathrm{G}$ raduate Medical Education, Department of Pathology and \\ Laboratory Medicine, Ascension St. John Hospital, Detroit, MI, USA
}

\section{Keywords}

Intussusception · Abdominal pain · Jejunal adenocarcinoma

\begin{abstract}
Intussusception is a rare phenomenon in adults and usually presents with bowel obstruction. Unlike child intussusception, adult intussusception is seldom idiopathic and frequently associated with secondary causes such as benign and malignant tumors. While most cases are treated surgically, emerging data suggest a more conservative management approach for patients with short-segment adult intussusception and without high-risk features such as bowel obstruction, mass seen on imaging, colon involvement, or constitutional symptoms of malignancy. We present a rare case of adult intussusception due to unsuspected adenocarcinoma of the jejunum, treated successfully with surgical resection followed by adjuvant chemotherapy. We favor the surgical rather than conservative approach for adult patients with intussusception to avoid missing unsuspected malignant tumors that are not readily visualized on imaging studies.

(C) 2020 The Author(s)

Published by S. Karger AG, Basel
\end{abstract}

\section{Introduction}

Bowel intussusception represents a rare kind of bowel obstruction and is defined as telescoping the proximal loop of the bowel (intussusceptum) within the distal loop 
(intussuscipiens), resulting in obliteration of the lumen [1,2]. While commonly encountered in children, adult intussusception (AI) is extraordinarily rare with an estimated incidence of be 2 cases/1,000,000 population/year [3, 4]. Child intussusception is commonly idiopathic (primary) with the majority of cases involving the ileum but can rarely involve the stomach, colon, and the rest of the small intestine. It occurs most commonly in male children between 4 and 10 months of age $[1,5,6]$. Interestingly, tetravalent rotavirus vaccine is associated with a slightly higher risk of intussusception among vaccinated children (1.5 excess cases per $100,000)[7]$. On the other hand, AI is associated with underlying pathology (secondary) in $90 \%$ of the cases and equally affects males and females [1,8]. AI occurs in the small bowel in $52 \%$ of the cases and large bowel in 38\% with $10 \%$ involving the stomach and surgical stomas $[5,9]$. Clinical symptoms of AI are variable and often nonspecific. Patients can present with diffuse abdominal pain, nausea, vomiting, bloody stools, change in bowel habits, and/or abdominal distention. Clinical examination may reveal abdominal distention or diffuse abdominal tenderness, but it frequently does not show any abnormality. The ambiguity of these clinical findings and their similarity to many other more common conditions such as inflammatory bowel diseases, bowel obstruction due to peritoneal adhesions, and infectious gastroenteritis make the clinical diagnosis of AI rather challenging. Diagnosing AI requires high index of suspicion, which often necessitates the use of imaging studies such as computed tomography (CT) [1]. Notably, the widespread medical use of CT has increased the rate of preoperative diagnosis of AI [4]. While more than $80 \%$ of the cases in children can be reduced with hydrostatic enemas, the majority of AI cases require surgical intervention $[1,4,10]$. Untreated intussusception can be life-threatening, commencing with progressive bowel distension, which in turn results in an increase in the intralumenal pressure, leading eventually to microvascular ischemia, tissue necrosis with subsequent intestinal perforation, and peritonitis [2]. Therefore, early diagnosis and treatment of AI are critical to avoid these complications. In this report, we present a case of AI due to underlying malignant jejunal neoplasm that was effectively diagnosed and treated. We also discuss some of diagnostic procedures and therapeutic interventions employed in the management of AI.

\section{Case Presentation}

A 69-year-old nondiabetic female presented with altered mental status, nausea, vomiting, and diffuse abdominal discomfort for 3 days. She reported no hematochezia or melena but admitted poor appetite and $20 \mathrm{lbs}$ weight loss over the last 6 months. Her past medical history was positive for atrial fibrillation, rheumatoid arthritis, chronic obstructive pulmonary disease, and hyperthyroidism. She had a history of iron deficiency anemia for 2 years with nadir hemoglobin of 7.4. Esophagogastroduodenoscopy and colonoscopy performed 2 year prior to presentation revealed no source of bleeding. The patient was treated with oral iron supplementation with improvement of hemoglobin to 11.7. She had no prior abdominal surgeries. She smoked 5-9 cigarettes per day for more than 20 years but denied drinking alcohol or using illicit drugs. She reported no family history of malignancy. Examination revealed blood pressure of $139 / 70$, pulse of $91 / \mathrm{min}$, temperature of $97.6^{\circ} \mathrm{F}$, oxygen saturation of $100 \%$ on room air, and weight of $120 \mathrm{lbs}$. Her head and neck examination revealed mild exophthalmos without cervical or supraclavicular lymphadenopathy. Lung and heart examinations were normal. The abdomen was moderately distended with diffuse tenderness, and her extremities had no edema. 
At presentation, complete blood count (CBC) showed white blood cell count of 5,100/ $\mu \mathrm{L}$, hemoglobin of $8.4 \mathrm{~g} / \mathrm{dL}$, mean corpuscular volume of $81.9 \mathrm{fl}$, and platelet count of $172,000 / \mu \mathrm{L}$. CBC 1 year prior showed hemoglobin of $10 \mathrm{~g} / \mathrm{dL}$. Upon admission, she was found to have glucose of $41 \mathrm{mg} / \mathrm{dL}$ (likely secondary to decreased oral intake), which was successfully treated by intravenous dextrose. After improvement of mental status and administration of adequate hydration, a CT scan of the abdomen and pelvis was performed and revealed high-grade intestinal obstruction due to small bowel intussusception (Fig. 1). A transition point was identified in the mid-pelvis, but no mass could be seen. Laparotomy confirmed intussusception (Fig. 2), and $10 \mathrm{~cm}$ of the mid-jejunum were resected. Pathology revealed jejunal moderately differentiated invasive adenocarcinoma measuring $5 \mathrm{~cm}$ with focal areas of necrosis (Fig. 3). There was no evidence of lymphovascular invasion. All surgical margins were negative, and only one out of three resected lymph nodes was positive. A CT scan of the chest revealed no evidence of metastatic disease. She was staged as $\mathrm{T}_{3} \mathrm{~N}_{1} \mathrm{M}_{0}$ (stage III). After recovering from the operation, she received 12 cycles of adjuvant chemotherapy with 5-fluorouracil, leucovorin, and oxaliplatin, which she tolerated well. Repeat CT scan after completion of therapy revealed no evidence of recurrence. Repeat CBC was normal with hemoglobin of $14.1 \mathrm{~g} / \mathrm{dL}$. She remains alive without evidence of disease 2 years after initial presentation.

\section{Discussion}

$\mathrm{AI}$ is a rare clinical entity with potential for severe complications if not promptly recognized and treated. It is often classified based on its location to entero-enteric (confined to the small intestine), colo-colic (confined to the large intestine), ileo-colic (when terminal ileum prolapses to the ascending colon), and ileo-cecal (when the ileo-cecal valve is the leading point of intussusception) [8]. It can also be classified based on its etiology to benign, malignant, and idiopathic. More than $90 \%$ of the pediatric cases are idiopathic [1]. Hypertrophy of lymphatic tissues in the terminal ileum, known as Peyer's patch, is thought to the leading point of intussusception in children and may be triggered by viral infections [6]. On the other hand, the etiology of AI includes carcinoma, Meckel's diverticulum, colonic diverticulum, lymphoma, lipoma, strictures, metastatic lesions, polyps, or inflammatory lesions. Adenocarcinoma accounts for $30 \%$ of all adult small intestine intussusceptions and $66 \%$ of the colonic intussusceptions $[1,11]$.

The classic presentation of child intussusception, which includes the triad of colicky abdominal pain, currant jelly stool, and a palpable sausage-shaped tender abdominal mass, is rarely encountered in adults. The majority of patients present with symptoms and signs of bowel obstruction. Although symptoms typically occur acutely, they can be subacute or chronic, particularly in colonic intussusception [1].

In children, abdominal ultrasound provides a rapid and sensitive screening test for intussusception and can reveal the "doughnut sign" and the "pseudo-kidney appearance" [6]. In adults, CT scan was found to be more accurate [12]. In one study, diagnostic accuracy of CT scan was reported to be nearly $100 \%[6,13]$. The CT appearance usually includes a "target," "bull's-eye," or sausage-shaped double-ring lesions. Alternatively, ultrasound was found to be less reliable in adults, owing to bowel edema, air-fluid levels, and larger fecal loads [6].

Treatment modalities for intussusception are variable. Because ileo-colic is the most common type seen in children, reduction is often successful by using pneumatic or hydrostatic edema. Moreover, entero-enteric intussusceptions usually reduce spontaneously. Alternatively, AI are historically treated surgically. Randomized clinical trials comparing operative 
and nonoperative approaches for AI are lacking. Yet, a recent study suggested that up to $82 \%$ of the radiologic intussusceptions can successfully and safely be treated nonoperatively. Nonetheless, this approach should be employed with great caution to avoid missing potentially serious underlying conditions such as malignancy. The operative approach is necessary in patients who present with bowel obstruction, those with mass seen on imaging, those with constitutional symptoms of malignancy (such as weight loss, anorexia, night sweats, etc.), and those with colo-colic and ileo-colic intussusception (given their higher association with malignancy) [14]. Adults with entero-enteric intussusceptions shorter than $3.5 \mathrm{~cm}$ and without any of the above-mentioned features are often self-limiting and may be considered for nonoperative management [15]. Our patient was treated surgically as she presented with small bowel obstruction and had significant weight loss (14\% of her body weight); both were concerning for underlying malignancy. When surgical intervention is performed, intussusception should be surgically reduced in children and resected in adults. If underlying malignancy is suspected, oncologic en bloc resection of the involved intestine and the associated mesentery should be sought. In colo-colic intussusceptions, preoperative colonoscopy can be useful in identifying underlying pathology and may assist in planning appropriate surgery. However, colonic biopsy should be performed with caution due to the increased risk for perforation due to tissue ischemia [6]. Prognosis of AI is largely dependent on the underlying pathology. If malignancy is found, appropriate antineoplastic therapy should be instituted postoperatively if clinically indicated.

In conclusion, AI can be a manifestation of serious conditions such as malignancy. While conservative management was proposed in low-risk patients, we favor the surgical approach to avoid missing potentially curable malignancy as in our patient. Oncologic surgery and subsequent antineoplastic therapy should be employed for these patients to optimize clinical outcomes.

\section{Statement of Ethics}

The patient provided written informed consent for publication. She was provided with a copy of the manuscript.

\section{Disclosure Statement}

All authors disclose that they have no conflicts of interest related to this study.

\section{Funding Sources}

The authors did not receive any funding.

\section{Author Contributions}

Tarik Hadid, MD, MPH, MS, obtained the consent from the patient, cared for the patient, gathered the patient data, reviewed the literature, wrote the initial draft of the manuscript, and revised the subsequent versions. Haidy Elazzamy, MD, reviewed the pathology of the 
resected specimen, prepared the pathology figure for the manuscript, and reviewed and edited the manuscript. Zyad Kafri, MD, MS, reviewed, edited, and supervised the process of constructing the manuscript to its final version.

\section{References}

1 Marinis A, Yiallourou A, Samanides L, Dafnios N, Anastasopoulos G, Vassiliou I, et al. Intussusception of the bowel in adults: a review. World J Gastroenterol. 2009 Jan;15(4):407-11.

2 Nkembe NM, Mbanga C, Agbor VN. Complicated Idiopathic Ileo-ileal Intussusception in a 45-year-old Male: A Case Report. Int J Case Rep; 2018. p. 2.

3 Manouras A, Lagoudianakis EE, Dardamanis D, Tsekouras DK, Markogiannakis H, Genetzakis M, et al. Lipoma induced jejunojejunal intussusception. World J Gastroenterol. 2007 Jul;13(26):3641-4.

4 Yalamarthi S, Smith RC. Adult intussusception: case reports and review of literature. Postgrad Med J. 2005 Mar;81(953):174-7.

5 Aref H, Nawawi A, Altaf A, Aljiffry M. Transient small bowel intussusception in an adult: case report with intraoperative video and literature review. BMC Surg. 2015 Apr;15(1):36.

6 Marsicovetere P, Ivatury SJ, White B, Holubar SD. Intestinal Intussusception: Etiology, Diagnosis, and Treatment. Clin Colon Rectal Surg. 2017 Feb;30(1):30-9.

7 Yih WK, Lieu TA, Kulldorff M, Martin D, McMahill-Walraven CN, Platt R, et al. Intussusception risk after rotavirus vaccination in U.S. infants. N Engl J Med. 2014 Feb;370(6):503-12.

8 Lu T, Chng YM. Adult intussusception. Perm J. 2015;19(1):79-81.

9 Brayton D, Norris WJ. Intussusception in adults. Am J Surg. 1954 Jul;88(1):32-43.

10 Jiang J, Jiang B, Parashar U, Nguyen T, Bines J, Patel MM. Childhood intussusception: a literature review. PLoS One. 2013 Jul;8(7):e68482-68482.

11 Chiang JM, Lin YS. Tumor spectrum of adult intussusception. J Surg Oncol. 2008 Nov;98(6):444-7.

12 Martín-Lorenzo JG, Torralba-Martinez A, Lirón-Ruiz R, Flores-Pastor B, Miguel-Perelló J, Aguilar-Jimenez J, et al. Intestinal invagination in adults: preoperative diagnosis and management. Int J Colorectal Dis. 2004 Jan;19(1):68-72.

13 Ciftci F. Diagnosis and treatment of intestinal intussusception in adults: a rare experience for surgeons. Int J Clin Exp Med. 2015 Jun;8(6):10001-5.

14 Rea JD, Lockhart ME, Yarbrough DE, Leeth RR, Bledsoe SE, Clements RH. Approach to management of intussusception in adults: a new paradigm in the computed tomography era. Am Surg. 2007 Nov;73(11):1098-105.

15 Lvoff N, Breiman RS, Coakley FV, Lu Y, Warren RS. Distinguishing features of self-limiting adult small-bowel intussusception identified at CT. Radiology. 2003 Apr;227(1):68-72. 


\section{Case Reports in Gastroenterology}

\begin{tabular}{l|l}
\hline Case Rep Gastroenterol 2020;14:27-33 \\
\hline DOI: 10.1159/000505511 & $\begin{array}{l}\text { @ } 2020 \text { The Author(s). Published by S. Karger AG, Basel } \\
\text { www.karger.com/crg }\end{array}$ \\
\hline
\end{tabular}

Hadid et al.: Bowel Intussusception in Adults: Think Cancer!

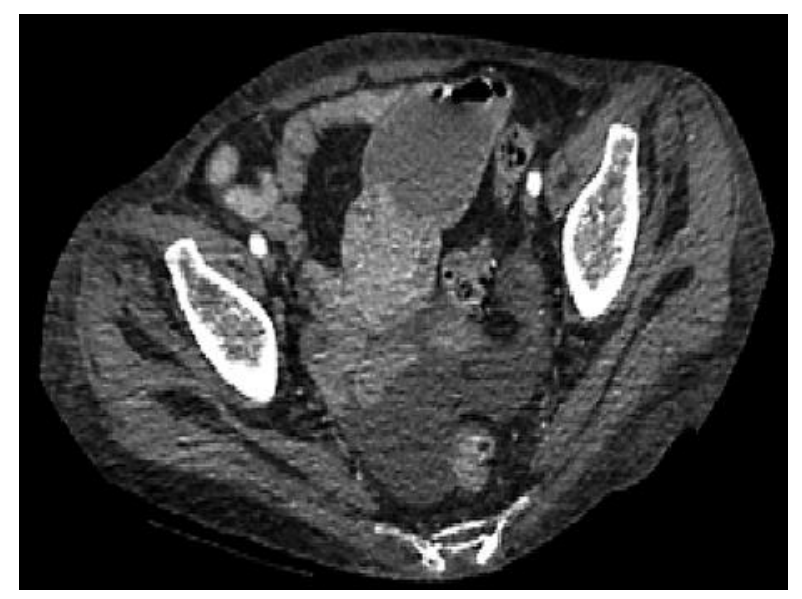

Fig. 1. CT scan of the pelvis showing small bowel intussusception.

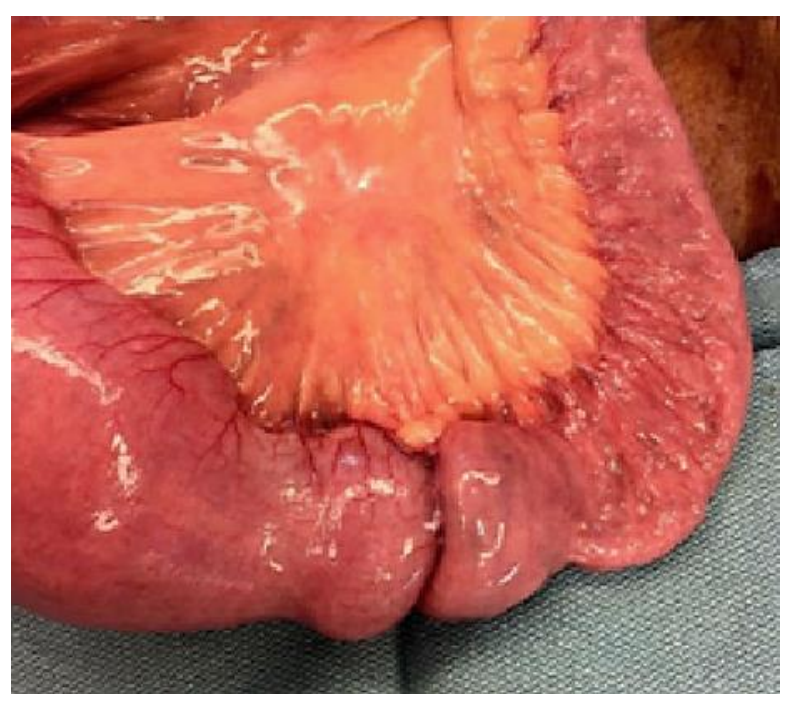

Fig. 2. Operative image showing intussusception of the jejunum. 


\begin{tabular}{|c|c|c|}
\hline \multirow{2}{*}{$\begin{array}{l}\text { Case Reports in } \\
\text { Gastroenterology }\end{array}$} & \multicolumn{2}{|c|}{ Case Rep Gastroenterol 2020;14:27-33 } \\
\hline & DOI: 10.1159/000505511 & $\begin{array}{l}\text { () } 2020 \text { The Author(s). Published by S. Karger AG, Basel } \\
\text { www.karger.com/crg }\end{array}$ \\
\hline
\end{tabular}

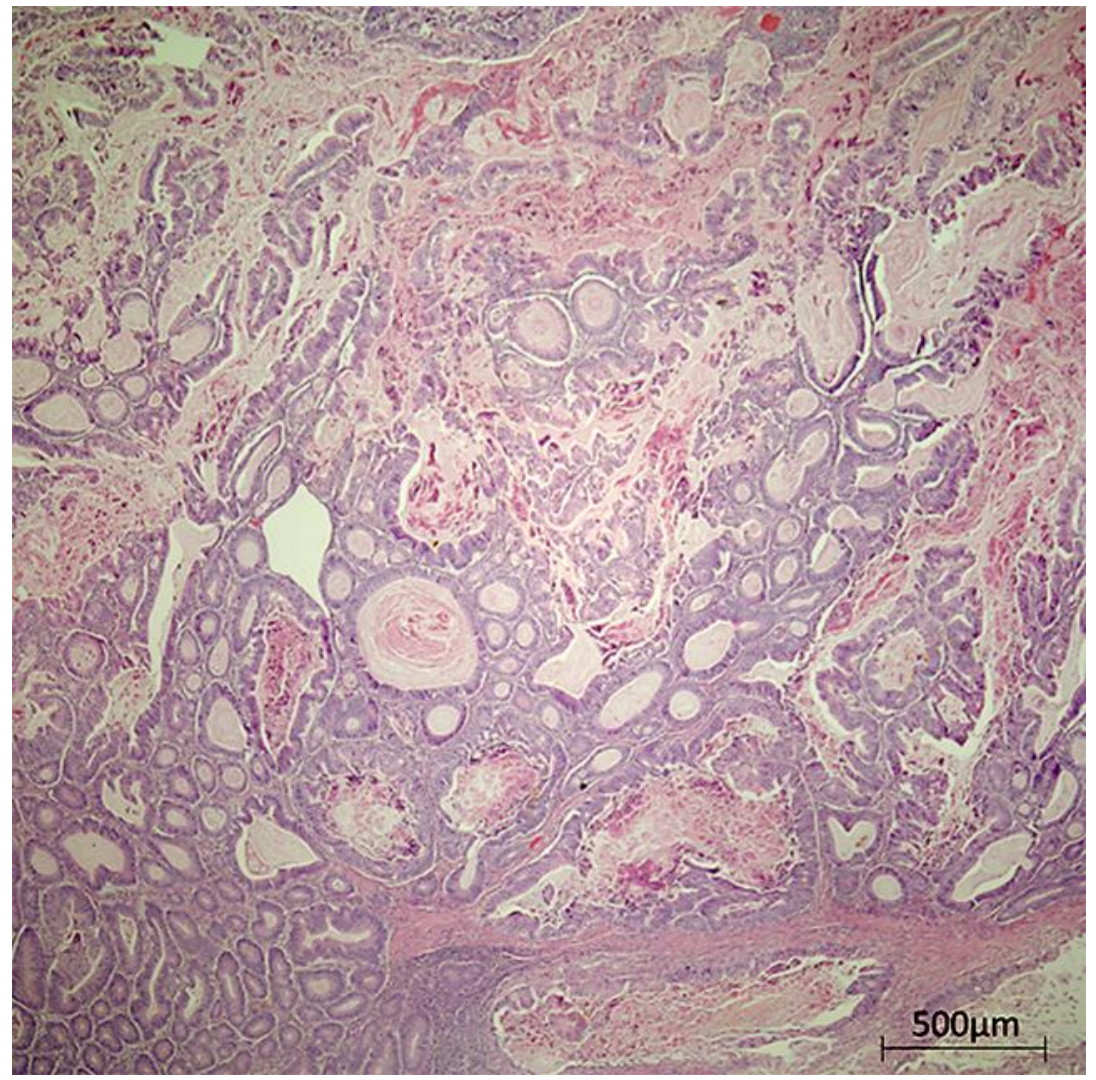

Fig. 3. Hematoxylin and eosin-stained section of the resected jejunum showing gland-forming malignant cells, consistent with adenocarcinoma (magnification $\times 40$ ). 